\title{
Alegorias do contemporâneo: articulações e efeitos entre identidades culturais e consumo
}

Luis Fernando Lazzarin*

\section{Resumo}

Este trabalho investiga como vêm sendo produzidas, na publicidade, diferentes articulaçôes entre identidades culturais e consumo. São apresentadas análises de dois vídeos publicitários da Natura Cosméticos S. A. e outros dois da Coca Cola Company. Os vídeos referidos são concebidos como pedagogias culturais não-escolares, pois, embora não possuam um currículo no sentido escolar de planejamento e de organização daquilo que deve ser ensinado, produzem diferentes modos de ser e de pertencimento. A análise levanta diferentes alegorias colocadas em circulação nos vídeos: a naturalização das identidades culturais e sua utilização como recurso; a relação cada vez mais íntima entre consumo e cidadania; o pertencimento e a solidariedade por meio do consumo, que prescinde de fronteiras geográficas. Captar e descrever esses elementos e seus sentidos parece ser extremamente importante para a formação dos futuros professores. Isso implica aprender a negociar com os apelos e as imposiçóes do consumo e permite oferecer resistência (ou seja, cria possibilidades de escolha) em meio ao que parece ser uma força avassaladora da contemporaneidade.

Palavras-chave: Educação; Pedagogias culturais; Consumo.

\footnotetext{
* Professor doutor da Universidade Federal de Santa Maria, Santa Maria, Rio Grande do Sul, Brasil.
} 


\section{Allegories of the contemporary: articulations and effects between cultural and consumption identities}

\section{Abstract}

This paper investigates the ways through which different articulations between cultural and consumption identities have been produced in advertising. It analyzes two advertising videos of Natura Cosmeticos S.A. and two of Coca Cola Company. For analysis purposes, the videos have been regarded as non-school cultural pedagogies because, although they do not have a curriculum in the form of school planning and organization of what should be taught, they produce different ways of being and belonging. The analysis evidences that different allegories have been spread by the videos: the naturalization of cultural identities and their use as resources; the increasingly closer relationship between consumption and citizenship; the feeling of belonging and solidarity by means of consumption, which does not know geographical borders. Capturing and describing such elements and their meanings seem to be extremely important to teacher education. This involves learning to deal with consumption appeals and impositions, and offering resistance (i.e. it generates possibilities of choice) amidst what seems to be an overwhelming power in contemporaneity.

Keywords: Education; Cultural pedagogies; Consumption.

As análises que compóem este trabalho derivam do interesse em investigar como vêm sendo produzidas articulaçóes entre identidades culturais e consumo na publicidade atualmente. Para isso, elegemos como materialidade de análise cinco vídeos de duas campanhas publicitárias veiculadas na Internet pelo sítio Youtube.com (quadro abaixo) que, a nosso ver, apresentam a temática referida.

\begin{tabular}{|l|c|l|}
\hline \multicolumn{1}{|c|}{ Título do vídeo } & Duraçáo & \multicolumn{1}{c|}{ Disponível em } \\
\hline $\begin{array}{l}\text { Natural é você pintar } \\
\text { a sua cara }\end{array}$ & $0: 35$ & http://www.youtube.com/watch?v=sF1zk-Q5gaM \\
\hline Natura Ekos & $1: 01$ & http://www.youtube.com/watch?v=GnkflSUrE7Y \\
\hline Happiness machine & $2: 04$ & http://www.youtube.com/watch?v=lqT_dPApj9U \\
\hline Fronteiras & $1: 03$ & http://www.youtube.com/watch?v=6LJeSpancSU \\
\hline
\end{tabular}

Para fins de análise, concebemos os vídeos referidos como pedagogias culturais não-escolares que se utilizam de alegorias para produzir e colocar em circulação diferentes relaçóes entre identidades culturais e consumo. Para os Estudos Culturais, todo conhecimento é cultural, ou seja, constituído como um sistema de significações e, nessa condição, vinculado diretamente a relaçôes de poder. Nessa abordagem, incluem-se "instâncias e processos culturais táo diversos quanto escolas, museus, filmes, livros de ficção, turismo, ciência, televisão, publicidade, medicina, artes visuais, música" (SILVA, 1999, p.139). Pedagogias culturais são essas instâncias e processos diretamente envolvidos na produção de identidades culturais, consideradas como modos de ser e de pertencimento, e de uma variedade de formas de conhecimento. 
As pedagogias culturais sempre ensinam algo, embora não possuam, necessariamente, um currículo no sentido de planejamento e de organizaçâo escolares daquilo que deve ser ensinado. Como consequência, apesar de ainda ocupar uma posição importante, é preciso ter em conta que a escola é uma dentre tantas instâncias culturais envolvidas na produção e na transformação de identidades culturais. De acordo com Silva (1999), ao invés de afastamento e polarização, o que se observa é uma permeabilidade e uma interpenetração entre as pedagogias culturais, genericamente, e a pedagogia escolar, especificamente. Aqui há uma aproximação de dois âmbitos, na medida em que o cultural se torna pedagógico e o pedagógico se torna cultural. Assim, é possível compreender a produção cultural de identidades como algo que se estabelece simbólica e discursivamente neste território de lutas por significação denominado "cultura" (COSTA, 2008), no qual grupos em diferentes posiçốes de poder disputam a imposição de seus significados.

Etimologicamente, alegoria vem do grego allous (falar) agouren (falar na ágora ou em público). Constitui-se em uma figura de linguagem que propicia dizer alguma coisa diferente do sentido literal, emprestando-lhe colorido e intensidade de expressão. Pode ser definida, também, como um conjunto ou um sistema coerente de imagens com significado (uma metáfora ampliada). Embora não tenha limites de extensão ou de linguagem (pode ocorrer em um poema, uma frase, um conjunto de sons, uma pintura, escultura ou, em nosso caso, um vídeo), distingue-se do símbolo, pois nele a compreensão se dá de forma direta e imediata (CEIA, 2015). A alegoria tem afinidades com a parábola e com a fábula, nas quais ocorrem a personificação de noçôes abstratas e o ensinamento de um preceito moral. Concebendo os vídeos como alegorias, buscamos interpretar o jogo entre os sentidos literais e figurados apresentados em sua narrativa audiovisual.

Compreendemos como sinais da contemporaneidade as problematizaçôes que as alegorias apresentadas nos vídeos veiculam, especialmente porque nos afastamos de uma perspectiva que argumenta que a indústria cultural levaria os consumidores a uma atitude passiva e acrítica. Discordamos, portanto, de uma abordagem que considera "os meios de comunicação de massa como simples instrumentos de manipulação e controle utilizados pela classe dirigente” (ESCOSTEGUY, 2004, p. 146-7). Não se trata, assim, de atribuir ao público consumidor uma atitude obediente aos ditames de uma indústria cultural que exerce seu poder verticalmente sobre mentes dóceis. Trata-se de entender as relaçôes entre mídia e consumidores de um ponto de vista produtivo, que náo compreende o exercício do poder em uma única direção, a partir de um único centro, de forma repressiva, mas como uma relação disseminada e capilarizada que percorre todos os níveis e hierarquias sociais. Acreditamos que se estabelecem relaçôes de força e de resistência ao mesmo tempo na produção material e no consumo, nas famílias, fábricas, sindicatos, partidos políticos, órgãos de base, meios de comunicaçáo de massa e estruturas de recepção que ressignificam suas mensagens (CANCLINI, 1998).

Compartilhamos com Sommer e Schmidt (2010) a afirmação de que, nos currículos de formação de professores, pouco se tem investido na análise e nos efeitos das 
pedagogias culturais, em comparação com o volume da produção acadêmica sobre o tema. Igualmente importantes, trata-se de formas de aprendizagem que interpelam um grande número de pessoas, uma vez que a sociedade "da mídia e da informação inventa estratégias que possam transpor barreiras de diferentes ordens - geográficas, culturais ou econômicas" (LUNARDI-LAZZARIN; MACHADO, 2010, p. 208).

Há inúmeras formas de análise, a depender das lentes teóricas e metodológicas que escolhamos para interpretar as alegorias dos vídeos. Ressaltamos que toda interpretação está sujeita à posição teórica, aos condicionamentos e à intuição de quem analisa. Por isso, os resultados deste artigo são localizados e temporais. Falamos de um lugar específico e em um tempo determinado. Desse modo, as conclusóes que trazemos neste trabalho são provisórias e sujeitas a revisóes e novas interpretaçôes.

\section{Natural é você pintar a sua cara: a naturalização das identidades culturais}

O vídeo intitulado "Natural é você pintar a sua cara" inicia com um fundo musical percussivo (vários tambores executam um ritmo cadenciado e forte). Diversas imagens de mulheres de diferentes culturas pintando a cara são mostradas em uma sequência rápida, sincronicamente com o ritmo dos tambores. Há mulheres que podemos identificar como indígenas, africanas, asiáticas, indianas e uma bailarina clássica, todas apresentadas em close-up. Subitamente, a sequência é interrompida por uma frase escrita com a pergunta "de onde vem essa sua vontade de pintar a cara"? Após alguns segundos com a pergunta congelada, o vídeo continua em um ritmo mais lento. Em seguida, uma canção modal - tipo de melodia geralmente associada às culturas apresentadas - é entoada em um registro agudo. As imagens são de uma mulher se pintando com sombra para os olhos, blush e rímel. A cara dessa mulher, que teria um ar de sofisticação e de quem só se viam os olhos, a boca e as faces enquanto ela pintava essas partes, é apresentada ao final, com a frase pronunciada por um locutor: "Natura Una, a melhor expressão de você mesma". A seguir, a percussão inicial retorna em um breve final, com os produtos Natura sendo apresentados no mesmo ritmo.

A resposta dada à pergunta "de onde vem essa sua vontade de pintar a cara?", no decorrer do vídeo, pode ser considerada naturalizante. A vontade de pintar a cara proviria de uma natureza comum às mulheres, náo importa a que cultura pertençam, muito embora, em cada cultura, elas tenham uma forma própria de fazê-lo. É interessante como o vídeo alinha as imagens de "natureza" e de "cultura" e as relativas noçôes de diversidade natural e de diferença cultural. Ao tomar esses conceitos como sinônimos, o vídeo abordaria as identidades culturais de forma totalizada, "intocadas pela intertextualidade de seus locais históricos, protegidas na utopia de uma memória mítica, de uma identidade coletiva única" (BABHA, 1987, p. 63). Isso significa dizer que a utilização da definição de diversidade cultural presumiria o estabelecimento de fronteiras definidas e rígidas entre identidades culturais puras, que, no limite, deveriam ser preservadas em nome da fantasia de uma origem legítima e autêntica. Pelos traços faciais, pela pintura e pela indumentária, as mulheres de cada cultura são apresentadas em padrôes típicos e característicos. Nesse sentido, o vídeo apresentaria uma 
linearidade "evolutiva", que começa com a pintura da cara de mulheres em culturas "primitivas" (indianas, negras, asiáticas) e que teria seu ápice na cultura ocidental contemporânea, na imagem de uma mulher executiva bem-sucedida, que seria, ao mesmo tempo, ideal de beleza e de sucesso profissional. Finalmente, a frase que encerra o vídeo ("Natura Una, a melhor expressão de você mesma") poderia indicar um reforço na "evolução cultural" apresentada.

\section{Natura Ekos: as identidades culturais como recurso}

No início do vídeo "Natura Ekos", o fundo musical parece ser o de um coraçáo pulsando. São apresentadas, em sequência, imagens do interior da floresta, com os raios de sol penetrando pelas copas das árvores, um rio, uma arara vermelha, os olhos de uma criança indígena em close-up, um raio cortando a escuridão do céu noturno, uma palmeira balançando ao vento. Ouve-se o vento assoviando, e lê-se na sequência das imagens: "Você é fruto, você é vento, você é semente, você é rio, você é bicho, você é raiz, somos produto da natureza". Enquanto o vídeo vai apresentando uma palavra de cada vez, as imagens de fundo alternam-se. Uma onça, um prédio da cidade grande, uma canoa no rio no meio da floresta, um ribeirinho escalando um pé de açaí, duas mãos abarcando um punhado de castanhas do Pará. Sucedem-se imagens da vida ribeirinha: uma cidadezinha de interior iluminada, uma festa popular com personagens fantasiados, homens caminhando pela floresta com seus balaios de produtos, novamente o rio ao entardecer, o sol se pondo, uma mulher e uma criança (mãe e filha?) com feiçôes caboclas. Ao final, uma tomada mostra todos os produtos da linha Natura Ekos.

A campanha parece-nos alinhar as imagens da sustentabilidade: os produtos seriam elaborados com matérias-primas provindas da natureza brasileira (da qual nós também fazemos parte), que não seria explorada de forma predatória (portanto, sem prejudicar a continuidade da produção nesta geração de brasileiros e nas vindouras) pelos brasileiros habitantes da floresta (que teriam o conhecimento para transformar as propriedades exóticas ou mágicas das plantas em cosméticos). O ciclo funcionaria graças a um comprometimento dos consumidores em vários níveis (afinal, o vídeo nos faz supor que é graças ao consumo dos produtos Natura que a floresta pode ser preservada e as comunidades ribeirinhas podem continuar a sobreviver em seu próprio ambiente, garantindo-se a continuidade da produção e a retomada de todo o ciclo).

Identidade cultural e consumo estariam, no vídeo, intimamente implicados com uma noção de cidadania que não diz respeito apenas ao exercício dos direitos oficiais, reconhecidos pelo Estado e relativos aos que nascem em um mesmo território, mas também às práticas culturais que "dão sentido de pertencimento e fazem com que se sintam diferentes os que possuem uma mesma língua, formas semelhantes de organização e de satisfação das necessidades" (CANCLINI, 2008, p. 46). Ser cidadão significaria, ao mesmo tempo, náo apenas ser contemplado com direitos básicos (de votar e de ser votado, à educação, à saúde, à habitação, ao saneamento básico, por exemplo). Também significaria ter atitudes, como consumidor, que influenciam os destinos da vida social e econômica da sociedade, como estar incluído no mercado 
de trabalho, participando das relaçóes econômicas sociais, gerando renda, adquirindo bens e usufruindo de serviços.

A articulação entre consumo, cidadania e identidades culturais, alegoricamente apresentada nos vídeos, pode ser aproximada do que Yudice (2004) diz em relação a um movimento contemporâneo no qual a cultura contém e expressa elementos importantes para os agenciamentos da sociedade civil, visando ao crescimento econômico, à solução de conflitos sociais e à criação de novas oportunidades de trabalho. $\mathrm{O}$ autor também analisa que esse processo de centralidade da cultura dá à esfera cultural um protagonismo maior das esferas concebidas como populares e tradicionais do que em qualquer outro período da história da modernidade. Nos vídeos analisados da Natura Cosméticos S.A., seríamos chamados a consumir de forma solidária e responsável. Mediante a escolha de consumir produtos formulados com matérias-primas da biodiversidade amazônica, produzidas por comunidades ribeirinhas autossustentáveis, sentir-nos-íamos moralmente justificados por exercermos nossa participação ativa e solidária, simultaneamente como cidadãos e como consumidores.

\section{Consumo e felicidade: Happiness machine}

No vídeo "Happiness Machine”, da Coca-Cola Company, a máquina da felicidade é instalada em um restaurante de uma universidade e, assim que é acionada por um consumidor/estudante, passa a servir, além da Coca-Cola, outros produtos. No início do vídeo, um subtítulo descreve o que está acontecendo: "Nós colocamos uma máquina especial de Coca-Cola em um campus para dividir um pouco de felicidade com o corpo estudantil". A seguir, esperando que a máquina despeje uma embalagem padrão de Coca-Cola, os estudantes são surpreendidos de várias formas ao utilizarem a máquina: ela fornece inúmeras embalagens do produto a uma garota. Todos são atraídos e, em meio a gargalhadas, ela distribui as garrafas extras que recebeu. Todos ficam muito alegres e barulhentos. A partir daí, a cada ficha colocada para retirar refrigerante, a máquina surpreende cada vez mais: uma mão humana sai da máquina (tudo indica que há uma pessoa no seu interior) e oferece vários buquês de flores e mais garrafas além do pedido. Uma estudante abraça a máquina e diz "obrigada, Coca”. Todos riem muito, abrem as garrafas e bebem com alegria. A mesma mão faz um cachorrinho com balóes de ar e o entrega a uma garota. E mais Coca. De repente, surge uma caixa de pizza de dentro da máquina. Mais gritos de alegria. E mais CocaCola. Todos bebem, comem e riem. Repentinamente, um sino toca, e um sanduíche interminável e gigantesco emerge de dentro da máquina. Os estudantes comemoram e correm para retirá-lo conjuntamente. O comercial termina com a imagem do sanduíche e com a pergunta escrita na tela: "Onde a felicidade vai atacar novamente"?

Percebemos um alinhamento entre as imagens de felicidade e o consumo de Coca-Cola. A máquina náo apenas forneceria refrigerante, mas produziria felicidade. Nesse sentido, a Coca-Cola não só venderia refrigerante, mas aproximaria as pessoas e faria com que todos se encontrassem em torno dela. A felicidade produzida seria diretamente proporcional à quantidade de Coca-Cola consumida. Muita Coca-Cola produziria muita felicidade. Portanto, quanto mais Coca-Cola consumíssemos, mais felizes seríamos. A máquina parece produzir a felicidade porque haveria um ser hu- 
mano dentro dela. O ser humano dentro da máquina ofereceria, pessoalmente, a felicidade em forma de Coca-Cola. Uma máquina humanizada, que saberia como produzir consumidores muito felizes. Finalmente, a felicidade pode atacar em qualquer lugar. Ela estaria espreitando em uma máquina de Coca-Cola. Não haveria fronteiras nem limites para o consumo, tampouco para a felicidade que ele traz.

Como dissemos no início do texto, não se trata de considerar a publicidade um instrumento de manipulação de audiências e de homogeneização de comportamentos. Trata-se de, a partir das alegorias midiáticas contemporâneas, entender as relaçóes entre identidades culturais e consumo não do ponto de vista da posse individual de objetos, "mas como apropriação coletiva, em relaçôes de solidariedade e distinção com outros, de bens que proporcionam satisfaçóes biológicas e simbólicas, que servem para enviar e receber mensagens" (CANCLINI, 2008, p. 70). Para além de atitude consumista, irrefreável e irracional, o consumo envolve o conjunto de processos em que se realizam a apropriaçáo e os usos dos produtos. Pelo consumo, apropriamo-nos náo apenas de mercadorias e serviços, mas de repertórios simbólicos que circulam, e estabelecemos relações de distinção, de pertencimento, de filiação.

\section{Fronteiras clandestinas}

A alegoria geográfica apresentada no vídeo "Fronteiras" é também interessante do ponto de vista das relaçóes aqui tratadas, entre identidades culturais e consumo. Em uma regiáo remota, duas sentinelas montam guarda. Marcham em paralelo à cancela, uma em cada lado da fronteira que limita o território dos dois países. O fundo musical, solenemente orquestrado, acentua a dramaticidade do momento e a atitude das sentinelas, pomposas e com feiçóes agressivas. Até que uma delas, castigada pelo calor, abre uma garrafa de Coca-Cola. O ruído da tampinha da garrafa é ouvido pela outra sentinela que, mesmo de costas, reconhece o som familiar. O desejo é percebido em sua cara e ela luta para náo delatar sua fraqueza diante do inimigo. Na ronda seguinte, ambas encontram-se novamente no centro da cancela. Momento de hesitação e reconhecimento. A sentinela que abriu a garrafa percebe o sofrimento silencioso do soldado do outro lado. Com o coraçáo amolecido, o dono da bebida saca a espada em um gesto enérgico e desenha com ela, na areia abaixo da cancela, uma meia lua que penetra no território do seu próprio país. Uma nova fronteira é desenhada na areia. A fronteira rígida se desfaz quando a garrafa de Coca-Cola é colocada no espaço clandestino, abaixo do oficial. O soldado sedento apanha a garrafa e satisfaz o desejo e a sede. Porém, o olhar de agradecimento rapidamente desaparece, e recomeça a animosidade. Não é possível ser simpático, quiçá amigo, uma vez que a fronteira oficial exige separação. As sentinelas voltam a marchar na vigilância interminável da fronteira.

Nesse vídeo, percebemos a articulaçáo e o alinhamento entre consumo e quebra de fronteiras. $\mathrm{O}$ consumo não respeitaria fronteiras nacionais. Até o último e mais afastado rincão, no meio do deserto, seria alcançado pelo consumo. Tempo e espaço entrariam no jogo de sentidos do vídeo. Os uniformes das sentinelas são anacrônicos, com penachos e medalhôes, e seus gestos são exageradamente agressivos, sugerindo que a cena acontece em um século passado ou entre culturas "atrasadas" e "paradas" 
no tempo (que ainda utilizam esse tipo de uniforme). Percebe-se que mesmo essas culturas distantes (temporal e geograficamente) seriam afetadas e fariam parte das relaçóes de consumo. O consumo poderia provocar sentimentos de solidariedade e ajudar a diminuir ou eliminar inimizades.

Finalmente, a ideia de clandestinidade. Uma nova fronteira, clandestina, seria desenhada pelo soldado que repassa a Coca-Cola ao inimigo, logo abaixo da cancela que delimita oficialmente o que é "nosso território" e o que é o "território deles". Poder-se-ia sugerir que essa atitude é uma alegoria para o quanto os limites culturais são flexíveis e fluidos, e que existe um trânsito de repertórios que não seria controlável pelo poder oficial e regulamentar. A fronteira seria negociada, rearranjada e redesenhada conforme a conveniência e a necessidade de quem participasse da cultura. Fica em aberto uma questão: quem poderia e quem não poderia manipular o limite fronteiriço? No caso do vídeo, quem fez isso foi uma sentinela, figura que encarna o poder oficial. Haveria outros agentes capazes disso? Quais?

\section{Considerações finais}

Percebemos um aspecto presente nos vídeos analisados até aqui: o consumo nos uniria. Sentir-nos-íamos identificados e teríamos uma sensação de pertencimento de várias maneiras: compartilhando uma identidade de "cidadão brasileiro" (ao consumir de forma sustentável os produtos Natura); celebrando alegremente o prazer de estarmos juntos em volta de uma happiness machine; tendo a oportunidade de burlar fronteiras e de reconhecer o outro para tornar a convivência com ele mais suportável. O consumo aproximaria pessoas e culturas. Consumo e solidariedade náo se excluiriam mutuamente.

É nesse sentido que entendemos que os vídeos analisados neste texto podem ser tomados como alegorias dos processos contemporâneos de globalização. Em relação a eles, é preciso ter em conta as confrontaçóes e as recusas, as discriminaçóes e as hostilidades constituintes dos contatos, cada vez mais intensificados, entre as diferentes culturas. Percebem-se, também, os efeitos que esses contatos interculturais produzem nas diferentes formas de vida e de pertencimento. Contribuem para esse processo a velocidade cada vez mais rápida da troca de informaçóes por meio das mídias eletrônicas e das tecnologias de produção e transmissão de dados, as facilidades das viagens internacionais e a expansão dos mercados produtores e consumidores, que prescindem de fronteiras nacionais. Esses fatores proporcionam um encurtamento das distâncias entre os diferentes grupos humanos. "O mundo se torna, em realidade e em experiência, mais interconectado” (HALL, 2006, p. 67).

Experimentamos esse processo cotidianamente e de várias maneiras: quando acessamos a Internet para ler e enviar e-mails ou fazer amizades e conhecer pessoas virtualmente ao redor do globo pelas redes sociais (Facebook, Twitter); quando colocamos no Instagram uma foto que acabamos de fazer em nossas férias no Rio de Janeiro; quando apanhamos uma Coca-Cola numa happiness machine; quando assistimos ao noticiário sobre o desempenho das bolsas de valores da Europa ou sobre um terremoto no Japão; quando compramos e consumimos um produto da linha Ekos Natura. 
Entretanto, a globalização não pode ser entendida unicamente como sinônimo de homogeneização e de eliminação das identidades culturais. $\mathrm{Na}$ análise dos vídeos da Natura Cosméticos S. A., observamos que elas são visibilizadas e valorizadas como marca de autenticidade que agrega valor aos produtos. Ou seja, aos produtos são associados significados que remetem a uma distinção, diferenciação e sofisticação justamente por sua originalidade e autenticidade culturais. Os produtos são elaborados de forma cuidadosa e artesanal, com matérias-primas que existem unicamente nas florestas brasileiras, vinculação que pode ser percebida na própria razão social da empresa e na sua linha de cosméticos Ekos.

A partir dos vídeos analisados, percebemos que a diferença cultural tem um lugar garantido nas práticas hegemônicas da globalização de duas maneiras: tanto pela via das lutas políticas quanto pelo fato de que a própria diferença pode ser transformada em mercadoria de consumo. As diferenças culturais, na medida em que são tomadas como mercadorias, além dos lucros, garantem aos mercados ao mesmo tempo uma comprovação de civilidade de práticas "politicamente corretas" (CARVALHO, 2010).

Os vídeos, enquanto alegorias, isto é, como formas que a linguagem assume para dar sentido e produzir a realidade, utilizam-se de elementos musicais e visuais, em alguns casos, bastante complexos para a análise. Garimpar esses significados é uma forma de atentar para as instâncias contemporâneas que, tanto quanto a escola, estabelecem modos de ser e de viver. Captar e descrever esses elementos e seus sentidos parece-nos ser extremamente importante para a formação dos futuros professores.

Vale a pena mencionar, mesmo que de forma resumida, o conceito de modo de endereçamento, citado por Costa (2008). Ele pode tornar-se útil, possibilitando a pergunta: quem o vídeo quer que eu (espectador) seja? Um vídeo publicitário tenta dar uma resposta quando imagina um público a quem pretende dirigir-se. Na medida em que essa imagem ideal coincide com a audiência real, o vídeo comunica-se e produz efeitos que eram esperados. Se, no entanto, há discrepâncias entre a recepção do público real e aquela imaginada, o vídeo terá sérios problemas de comunicação de sua mensagem. Nesse caso, há problemas e complicaçôes no modo de endereçamento. De uma forma esquemática, o "acerto" ou o "erro" do vídeo é uma questão de reconhecermo-nos nele ou não.

Estar atento para os endereçamentos que a todo o momento a mídia e a publicidade fazem significa estabelecer um espaço de manobra em que se procure identificar esses "erros" e esses "acertos" nos endereçamentos e perceber como se pode negociar com eles, isto é, poder decidir em que momentos é interessante ou não aceitar este ou aquele endereçamento. Isso implica negociar com os apelos e as imposiçóes do consumo e permite que se ofereça resistência (ou seja, cria possibilidades de escolha) em meio ao que parece ser uma força avassaladora da contemporaneidade.

Nessa esteira é que entendemos a importância da proposição de análises desse caráter para a formaçấo de professores. Buscamos possibilidades que permitam criar modos alternativos de abordar a formação pedagógica, que, a nosso ver, diz respeito 
não somente ao que está instituído na e pela escola, mas também ao que circula em outros espaços, como a publicidade.

\section{Referências}

BHABHA, H. O local da cultura. Belo Horizonte: UFMG, trad. Myriam Ávila, Eliana Reis, Gláucia Gonçalves, $4^{\mathrm{a}}$ reimpressão, 1987.

CARVALHO, R. T. de. Diferença cultural mercado e mídia. In: BURITY J. A.; RODRIGUES, C. M. L.; SECUNDINO, M. A. (Orgs.). Diferenças culturais \& políticas de identidade. Belo Horizonte : Argvmentvm Editora, 2010, v. 2, p. 51-62.

CEIA, C. Sobre o conceito de alegoria. Disponível em: <http://www.pgletras.uerj.br/matraga/nrsantigos/matraga10ceia.pdf>. Acesso em: 02 mar. 2015.

COSTA, M. V. Currículo e pedagogia em tempos de proliferação da diferença. In: XIV ENCONTRO NACIONAL DE DIDÁTICA E PRÁTICA DE ENSINO, 3, 2008, Porto Alegre. Anais... Trajetórias e processos de ensinar e aprender: lugares memórias e culturas, livro 3, 2008, p. 1-14.

ESCOSTEGUY, A. C. Estudos culturais: uma introdução. In: SILVA, T. T. (Org.) O que é, afinal, estudos culturais?. Belo Horizonte: Autêntica, 2004, p. 133- 223.

CANCLINI, N. G. Culturas híbridas: estratégias para entrar e sair da modernidade. São Paulo: Edusp, trad. de Ana Regina Lessa e Heloísa Pezza Cintrão, 1998.

Consumidores e cidadáos. Rio de Janeiro: Editora da UFRJ, 2008.

HALL, S. Identidades culturais da pós-modernidade. Tradução de Tomaz Tadeu da Silva e Guacira Lopes Louro. Rio de Janeiro: DP \& A, 2006.

LUNARDI-LAZZARIN, M. L.; MACHADO, F. de C. Outros domínios pedagógicos: a mídia ensinando sobre a mesmidade e a alteridade. Revista Educação Especial, Santa Maria, v. 23, n. 37, p. 207-216, 2010.

SILVA, T. T. Documentos de identidade: uma introdução às teorias do currículo. Belo Horizonte: Editora Autêntica, 1999.

SOMMER, L. H.; SCHMIDT, S. Formação de professores e consumo: um debate necessário, São Leopoldo, Revista Educaçáo, v. 14, n. 3, p. 215-221, 2010.

YUDICE, G. A conveniência da cultura. Tradução de Marie Anne Kremer. Belo Horizonte: UFMG, 2004.

\section{Correspondência}

Luís Fernando Lazzarin - Universidade Federal de Santa Maria, Centro de Educação.

Av. Roraima n. 1000, Camobi. CEP: 97105-900 - Santa Maria, RS - Brasil.

E-mail:1lazza@hotmail.com

Recebido em 16 de junho de 2015

Aprovado em 08 de agosto de 2015 